\title{
Examining Factors Contributing to Indiscipline in Primary Schools in Nyeri Central Sub-County, Kenya
}

\author{
Patrick Kagoiya ${ }^{1}$, Njogu Kagema ${ }^{1 *}$ \\ ${ }^{1}$ Karatina University, Department of Planning, Administration and Curriculum Development, Karatina, KENYA
}

*Corresponding Author: jkagema@karu.ac.ke

Citation: Kagema, N. and Kagoiya, P. (2018). Examining Factors Contributing to Indiscipline in Primary Schools in Nyeri Central Sub-County, Kenya. Pedagogical Research, 3(2), 07. https://doi.org/10.20897/pr/91650

Published: June 03, 2018

\begin{abstract}
School discipline is a core indicator of school effectiveness. Learner management is crucial and educational researchers need to focus on factors leading to indiscipline in schools. Guided by Planned Behaviour Theory that explores on guidance, counseling and good classroom management the study used the survey research design to sample 91 teachers randomly selected from 13 schools. Purposive sampling was used to select 13 head teachers. The research instruments used was Head Teachers' and Teachers' Questionnaire with a reliability coefficient of 0.76 . Data obtained was coded and analyzed quantitatively using Statistical Package for Social Sciences (SPSS ver. 19). Its presentation was done by use of charts, tables, percentages and frequencies. The study found out that $55 \%$ of the teachers used guidance and counseling in enforcing discipline in schools while $7.1 \%$ ) still use corporal punishment. The study concludes that absenteeism, truancy and lying were found to be prevalent in many schools and those teachers and parents are to take a great role in discipline management of learners. We recommend re-training of teachers on alternative methods of discipline. It is expected that the findings of the study will benefit education policy makers to use acceptable disciplinary procedures in schools.
\end{abstract}

Keywords: school discipline, learners, teachers, classroom management

\section{INTRODUCTION}

Indiscipline is the most common challenge faced by teachers all over the world. Researchers have been studying various ways of managing discipline and the studies will continue for as long there will be schools. Maphosa (2011) assert that the issue of learners' indiscipline has taken centre stage for a long time both internationally and nationally. According to these authors in the United Kingdom, for example, there are many cases of classroom disorders. A lesson depends on many factors to reach at an acceptable level of success, discipline takes the lead. In a classroom, discipline is prerequisite if meaningful learning is to take place. Nakpodia (2010) defines discipline as methods of modelling character and teaching self-control and acceptable behaviour. It implies self control, restraint, and respect for self and others.

Indiscipline on the other hand, is disrespect for school authority, disobedience of set rules and regulations and non-maintenance of established standards of behavior. School rules are usually associated with classroom management and school discipline. However, rules also define ways of thinking about oneself and the world. Rules are guidelines for actions and for the evaluation of actions in terms of good and bad, or right or wrong, and therefore a part of moral or values education in school. School discipline can be described as all the strategies that can be used to coordinate, regulate and organize individuals and activities in the school (Thornberg, 2008). 
Discipline aims at helping an individual to be well adjusted and happy (Nakpodia, 2010). In order to maintain an academically focused environment for teaching and learning in the classroom, some standard of behavior must be encouraged. Zubaida (2009) asserts that one purpose of discipline is to provide conditions which promote learning. Discipline is meant to discourage disorderly conduct that may threaten safety in the classroom.

Most common behavioral problems among learners include truancy, fighting, shouting, snatching other learners' property, bullying, cheating, viewing pornographic materials, threatening teachers among others (Zubaida, 2009). Boroffice (2004) believes that factors such as biological social, view of self, attitudes, beliefs, sense of his future are some of the factors that predispose adolescents to unhealthy behaviours and this is collaborated by Etesi (2012) who has consistently shown that suspensions, expulsions and other punitive consequences are not the solution to indiscipline. Out-of-school suspension is ineffective in remediating discipline problems because many learners do not view it as punishment. Removing the offending learner from the classroom prevents him or her from learning and provides no means for preventing or reducing future misbehavior.

\section{KENYAN CONTEXT AND BACKGROUND}

One of the most contentious issues in school discipline is the use of corporal punishment to enforce discipline. In the Kenyan context, Legal Notice 40/1972 contained in the Education Act Cap 2011 (revised 1980), authorized the use of the cane, albeit with specific guidelines for its application. Unfortunately, some teachers failed to adhere to these guidelines. This use of corporal punishment sometimes has resulted in serious injuries to learners and in a number of cases even death. An example of this is an incident that was reported in the press (Daily Nation Jan 25,2001 ) where a ten-year old learner at a Nyeri school collapsed and died after being beaten by a teacher, allegedly because, the learner did not have a games kit. Such consequences resulted in pressure from non-governmental organizations and international agencies to ban corporal punishment in Kenyan schools. They argue that, it is against provisions in international instruments on child protection to which Kenyan Government is signatory (MOEST, 2005). Corporal punishment has been linked to school vandalism increased and higher rates of misconduct. In fact, for some learners, corporal punishment can create negative attitudes, reinforce the kind of behaviour that was intended to be punished, and lead to increased discipline problems (Etesi, 2012).

What this tells us, is that suspensions, expulsions and corporal punishment do little to help learners acquire new and responsible behaviour to replace the ones that are not working for them or for the school as a whole. What is even worse is that such punitive measures ultimately have the effect of taking responsibility away from the learner because they are never asked to reflect on what they did, to fix any damage that was done or to plan to do better.

Teachers fail to control learners as their authority has been undermined (Etesi, 2012). Indiscipline in schools affects the learner more than anybody else. It is the learner who lose an opportunity to learning time when under punishment. When through with school their behavior affects the community directly and indirectly politically, economically and socially (Donga, 1998). Politically, the government will be bound to hire skilled people to take up government jobs other than school drop outs. These learners lack skills required to perform their duties. Economically the government spends money funding education, for instance though Free Primary Education and Free Secondary Education.

When children drop out of school, that money will be wasted. The government educates the nation in order to provide the country with professionals who will boost the economy in future. Socially, crime rate will be uncontrollable because these children will commit crimes to satisfy their basic needs for example food, and clothing. Indiscipline in the classroom is a phenomenon which requires the attention of all those who are involved in teaching and as alluded to by Zubaida (2009), there is need to get at the root causes of this problem amongst learners with a view to finding a solution.

It is the researcher's belief that the desired outcome of any effective discipline system is to change learner's bad behaviour to good behaviour. Teaching learners to adapt good behaviour is one of the most effective means of establishing a safe orderly and academically productive classroom and school wide environment. Learners come to school with unique values and sense of right and wrong. It is therefore the teachers' responsibility to teach them the expected behaviour. Etesi (2012) believes that teachers should provide assistance to children as they learn to assume greater responsibility for themselves and gain more control over their behaviour. This implies that teachers must find ways to create a climate of co-operation in order to teach learners the academic, social and emotional skills they must possess to function successfully at home, school and in the community. 


\section{GROUNDING THEORY}

The study was guided by the Theory of Planned Behaviour as proposed by Ajzen (1991). This theory suggests that behaviour is dependent on an individual's intention towards performance which is determined by one's attitude and subjective norms beliefs about what other people think the person should do or general social pressure. Character is also determined by an individual's perceived behavioral control, defined as an individual's perceptions of their ability or feeling of self-efficacy to behave. Intention is the most important variable in predicting behaviour change, suggesting that behaviour is often linked with one's personal motivation.

This suggests that it may be important to present information to help shape positive attitudes like discipline of learners by stressing subjective norms based on opinions learners have which may not be based on facts but supports discipline. For perceived behaviour control to influence behaviour change, much like self-efficacy a person must have, a realization, willing and have the ability to perform the behaviour. When repeated severally it becomes a habit, hence learning a new skill. Teachers need resources and skills for the change process of use of corporal punishment to deal with indiscipline to use of alternative methods.

\section{SELECTED FACTORS CONTRIBUTING TO LEARNERS INDISCIPLINE: A REVIEW OF LITERATURE}

Absenteeism is a major area of indiscipline in schools. Hogg and Reid (2006) in their study report a positive correlation between performance and school attendance, namely that parenting styles contribute to students' indiscipline. They further argue that social identity perspective and communication research represent a truly integrative force for the communication discipline. This is one area that schools should cultivate to enable communicative discipline among pupils. The fact is that dysfunctional behavior from parents can lower the performance of students. A similar survey was carried out by Lynskey, Hall and Louis (2003) on the effect of adolescents' use of cannabis sativa on education attainment. The cross-sectional study revealed a significant association between cannabis sativa use and a range of measures of education performance including lower grade point average (GPA) and poorer school performance. The use of cannabis sativa was associated with the adoption of an anti-conventional lifestyle resulting in a lot of indiscipline in schools. The use of cannabis sativa was also identified as a cause of indiscipline in many schools in Kenya (Republic of Kenya, 2001) but also failed to give remedies to the indiscipline cases in public schools in Kenya. Teachers have been unable to detect the drugs in school as they concentrate on their core duty of teaching (Lynskey, Hall and Louis, 2003). Teacher's shortage in schools has also affected learners monitoring in schools.

Rwamba (2004) argued that lack of democratic leadership together with communication breakdown is a major cause of indiscipline in schools. He suggested that there is a relationship between learning and indiscipline. Cognitive skills are crucial in terms of academic success, self-esteem, coping skills and overall resilience. In the absence of discipline, the learning and teaching process are hindered. Time is wasted and energy is misdirected to deal with issues emanating from unrest. Rwamba (2004) failed to show how lack of democratic leadership and communication should be enhanced to promote discipline in schools.

Although much has been done to establish the causes of the problem of unrests and possible remedies recommended, very little has been done in terms of the counseling needs of the parties affected by unrests Lochan (2010). Such counseling would be important in deterring future occurrences and bringing normalcy to the schools. For example, the best that is usually done is to expel or suspend the students and when they come back to school, a penalty is imposed for damages incurred. Usually such actions breed deeper resentment and the teachers and learners need to co-exist in the same school. Without counseling and proper "friendship" between administration and teachers on the one hand and the students on the other, such a problem is rarely solved. In order to deal with a problem effectively it is essential to have a clear understanding of the underlying reasons behind the problem (Lochan, 2010).

No amount of teaching or respect will make discipline effective unless reasons why the behavior occurred are understood. This section therefore focuses on factors contributing to learners' indiscipline at home and in school. A fundamental issue when attempting to probe indiscipline amongst learners is to understand its causes. Factors that cause indiscipline are as diverse as the individuals involved. The causes could be social, economic, psychological, peer influence, and child environment.

Many school problems cannot be dealt with in isolation. Various family circumstances may exert more powerful influences over learner's behavior than anything that happens in school. Lack of discipline among learners is largely a reflection of attributes, values and practices of their society. If there is no social order in society learners will be indiscipline in school (Grossnicle and Frank, 1990). Discipline problems reflect problems in the home. Schools are microcosm of society, as problems like drug abuse, crime and physical abuse increase in society, so 
will the discipline problems in schools (Lochan, 2010). Thus, since schools exist as societal institutions they are bound to be influenced by whatever transpires outside them. A variety of family factors mediate classroom disruptive behavior.

Permissive home environments contribute to learner misbehavior. It is noted that if parents spend little time at home, children may seek unsuitable social experiences elsewhere that have devastating affects on their lives. In Zimbabwe, as an example many parents have migrated to neighboring countries or overseas, leaving their children under the guardianship of relatives or children to take care of themselves thus creating permissive environments for acts of misconduct. Evans and Miguel (2004) found out that Kenyan students who do not have the guardianship of biological parents had higher rates of misbehavior in schools.

Donga (1998) maintains that single parent home may play a dominant part in enhancing discipline in school. This is also in line with Etesi (2012) view that single parent homes are more likely to rear children with higher level of emotional, psychological and behavioral problems. The single parent is the sole breadwinner and as such cannot supervise children adequately. Most of the children as echoed by Donga (1998) are attracted to join gangs where they will enjoy the attention and protection that they have to do without at home.

Poverty is also perceived as a major cause of some forms of misbehavior in school (Evans and Miguel, 2004). When parents fail to meet learners' basic needs as stipulated by Maslow's hierarchy of needs (1970). Physiological needs include clothing, food, and shelter. Unless these basic needs are satisfied to the required extent, other needs do not motivate children to learn and as a result the child resorts to abuse behavior. Students may be involved in theft and prostitution in order to meet daily needs. Others may skip classes to engage in informal jobs as vendors.

Disruptive behavior in schools has been a source of concern for school systems for many years. Discipline problems reflect problems in the home. As problems like drug abuse, crime and physical abuse increase in society, so will the discipline problems in schools (Lochan, 2010). Harsh and lack of conducive environment from physical facilities to the school structures of administration may cause indiscipline. Undisciplined learners may also be the result of normal reactions to deficiencies in the school and to teachers as directors of the educational enterprise.

The head teacher may lack expertise in professional management, training and proper guidance and sometimes interfere with smooth running of institutions. They may also be ignorant of the Ministry's policies. Some unacceptable behavior displayed by some members in the school include making unrealistic demands on the school like nepotism, admitting children of relatives without paying school fees or having tenders being awarded to them. Some schools do not accept head teachers from religious denominations other than theirs, while other head teachers introduce programmes that run parallel to school programmes thus placing a lot of pressure on children (Kyungu, 2001).

Learners themselves are a source of indiscipline in schools. According to Cheunyane (2008) drugs taken by students are a contributing factor to indiscipline. Some students attend school while drunk. They assert that students form groups and take drugs or smoke drugs. They for instance, take their juices laced with intoxicants in front of unsuspecting teachers. In this state these learners are prone to commit other forms of indiscipline. The teacher's role is made more problematic when classrooms and schools become unmanageable. Teachers may waste special teaching time trying to settle disciplinary problems (Maphosa and Mammen, 2011).

\section{METHODOLOGY}

\section{Sample Size and Instrumentation}

A sample size of 13 schools was selected to represent schools and their representative head teachers selected purposively and also 91 teachers randomly selected. Research questionnaires were administered to the teachers and the Head teachers requiring them to state the rate of occurrence on various forms of indiscipline in their school, and how to deal with these forms of indiscipline during this era of the ban on corporal punishment.

\section{Reliability of the Instruments}

Test retest method was used to check the reliability of the instruments, obtained by administering the same test twice over a period of time to a group of individuals. This was done at Ihururu primary school in Nyeri Central Sub-County, Kenya a month before the actual study. Results of the tests were then correlated to obtain the reliability index of .76 hence the instruments sufficiently reliable.

\section{Data Analysis}

Data collected was analyzed quantitatively using SPSS v.23.0. Frequencies of occurrences and percentages were noted. Tables were drawn showing the frequencies of indiscipline occurrences and the percentages. From the tables, graphs were generated from the data in the tables and explanation was given below the graph to make it clear. 
Table 1. Frequency of Occurrence of Different Forms of Indiscipline

\begin{tabular}{|c|c|c|c|c|c|}
\hline \multirow[t]{2}{*}{ Indiscipline Case } & \multicolumn{5}{|c|}{ Frequency of Occurrence (\%) } \\
\hline & Very High & High & Average & Low & Very Low \\
\hline Absenteeism/Truancy & 9.4 & 17.6 & 7.1 & 21.2 & 44.7 \\
\hline Late coming & 9.4 & 11.8 & 3.5 & 24.7 & 50.6 \\
\hline Bullying & 4.7 & 4.7 & 11.8 & 8.2 & 70.6 \\
\hline Stealing & 4.7 & 4.7 & 20.0 & 27.1 & 43.5 \\
\hline Noise making & 26.5 & 32.9 & 20.6 & 16.5 & 3.5 \\
\hline Fighting & 4.7 & 47.1 & 15.3 & 20.0 & 12.9 \\
\hline Not finishing homework & 35.9 & 21.8 & 24.7 & 7.6 & 10.0 \\
\hline Use of foul language & 14.7 & 50.6 & 4.7 & 19.4 & 10.6 \\
\hline Vandalism & 7.1 & 4.7 & 22.4 & 12.9 & 52.9 \\
\hline Lying & 19.4 & 39.4 & 17.1 & 5.3 & 18.8 \\
\hline Indecency & 8.2 & 0 & 15.3 & 24.7 & 51.8 \\
\hline
\end{tabular}

\section{Ethical Consideration}

In the process of carrying out the research, honesty was observed in reporting the findings whereby there were no manipulations or undue assumptions. The responses gathered were treated with utmost confidence to protect the subject's privacy by not divulging the identities of the respondents. The subjects were also assured that the results obtained will be used for research purposes only whereby the findings obtained were not linked to any of the respondents and not used for any other purpose other than for academic purposes. Further, informed consent was sought in dealing with the subjects whereby the respondents were not coerced but allowed to choose by their free will to participate in the study.

\section{FINDINGS}

The objective of the study was to examine factors contributing to indiscipline in primary schools in Nyeri Central Sub-County. To achieve this objective, the researcher sought to establish the rate of occurrence of 11 different forms of indiscipline in their schools or classes. Tables 1 analyze the responses obtained.

Analysis of the findings in Table 1 shows that majority of the teachers (44.7\%) said that frequency of indiscipline cases involving absenteeism or truancy is very low, $21.2 \%$ said the cases are low, $7.1 \%$ of the teachers said they are average, $17.6 \%$ said that the cases are high and $9.4 \%$ of the teachers said the frequency of the cases was very high. Cumulatively, the findings indicate that majority of the teachers $(65.9 \%)$ perceive the frequency of indiscipline cases emanating from absenteeism and truancy as low and only $27 \%$ of the teachers perceive the frequency of the indiscipline cases associated with absenteeism and truancy as high. This implies that absenteeism and truancy are not significant causes of indiscipline.

About late coming, the findings indicate that majority of the teachers $(50.6 \%)$ said that frequency of indiscipline cases involving late coming is very low, $24.7 \%$ said the cases are low, $3.5 \%$ of the teachers said they are average, $11.8 \%$ said that the cases are high and $9.4 \%$ of the teachers said the frequency of the cases was very high. Cumulatively, the findings indicate that majority of the teachers $(75.3 \%)$ perceive the frequency of indiscipline cases emanating from late coming as low and only $24.7 \%$ of the teachers perceive the frequency of the indiscipline cases associated with late coming as high. This implies that late coming is not a significant cause of indiscipline.

On bullying, the findings indicate that majority of the teachers $(70.6 \%)$ said that frequency of indiscipline cases involving bullying is very low, $8.2 \%$ said the cases are low, $11.8 \%$ of the teachers said they are average, $4.7 \%$ said that the cases are high and $4.7 \%$ of the teachers said the frequency of the cases was very high. Cumulatively, the findings indicate that majority of the teachers $(78.8 \%)$ perceive the frequency of indiscipline cases emanating from bullying as low and only $21.2 \%$ of the teachers perceive the frequency of the indiscipline cases associated with bullying as high. This implies that bullying is not a significant cause of indiscipline. The small number of cases of bullying may be attributed to the fact that most of the pupils come from the same neighborhoods at home and therefore are familiar with each other thus reducing extent of hostilities against each other.

The issue of stealing indicates that majority of the teachers $(43.5 \%)$ said that frequency of indiscipline cases involving stealing is very low, $27.1 \%$ said the cases are low, $20.0 \%$ of the teachers said they are average, $4.7 \%$ said that the cases are high and $4.7 \%$ of the teachers said the frequency of the cases was very high. Cumulatively, the findings indicate that majority of the teachers $(70.6 \%)$ perceive the frequency of indiscipline cases emanating from stealing as low and only $9.4 \%$ of the teachers perceive the frequency of the indiscipline cases associated with stealing as high. This implies that stealing is not a significant cause of indiscipline. This may be attributed to the fact that majority of the schools are day schools and therefore the pupils do not bring to school any other property apart from books and stationery. 
On noisemaking, the findings indicate that $3.5 \%$ of the teachers said that frequency of indiscipline cases involving noisemaking is very low, $16.5 \%$ said the cases are low, $20.6 \%$ of the teachers said they are average, $32.9 \%$ said that the cases are high and $26.5 \%$ of the teachers said the frequency of the cases was very high. Cumulatively, the findings indicate that majority of the teachers $(59.4 \%)$ perceive the frequency of indiscipline cases emanating from noisemaking as low and only $40.6 \%$ of the teachers perceive the frequency of the indiscipline cases associated with noisemaking as high. This implies that noisemaking is a significant cause of indiscipline.

For fighting, the findings indicate that $12.9 \%$ of the teachers said that frequency of indiscipline cases involving fighting is very low, $20.0 \%$ said the cases are low, $15.3 \%$ of the teachers said they are average, $47.1 \%$ said that the cases are high and $4.7 \%$ of the teachers said the frequency of the cases was very high. Cumulatively, the findings indicate that majority of the teachers $(32.9 \%)$ perceive the frequency of indiscipline cases emanating from fighting as low and $51.8 \%$ of the teachers perceive the frequency of the indiscipline cases associated with fighting as high. This implies that fighting is a significant cause of indiscipline.

The findings indicate that $10.0 \%$ of the teachers said that frequency of indiscipline cases involving not finishing homework is very low, $7.6 \%$ said the cases are low, $24.7 \%$ of the teachers said they are average, $21.8 \%$ said that the cases are high and $35.9 \%$ of the teachers said the frequency of the cases was very high. Cumulatively, the findings indicate that majority of the teachers $(57.7 \%)$ perceive the frequency of indiscipline cases emanating from not finishing homework as high and only $17.6 \%$ of the teachers perceive the frequency of the indiscipline cases associated with not finishing homework as low. This implies that not finishing homework is a significant cause of indiscipline.

On use of foul language, the findings indicate that $10.6 \%$ of the teachers said that frequency of indiscipline cases involving use of foul language is very low, $19.4 \%$ said the cases are low, $4.7 \%$ of the teachers said they are average, $50.6 \%$ said that the cases are high and $14.7 \%$ of the teachers said the frequency of the cases was very high. Cumulatively, the findings indicate that majority of the teachers $(65.3 \%)$ perceive the frequency of indiscipline cases emanating from use of foul language as high and only $30.0 \%$ of the teachers perceive the frequency of the indiscipline cases associated with use of foul language as low. This implies that use of foul language is a significant cause of indiscipline.

The findings indicate that majority of the teachers (52.9\%) said that frequency of indiscipline cases involving vandalism is very low, $12.9 \%$ said the cases are low, $22.4 \%$ of the teachers said they are average, $4.7 \%$ said that the cases are high and $7.1 \%$ of the teachers said the frequency of the cases was very high. Cumulatively, the findings indicate that majority of the teachers $(65.8 \%)$ perceive the frequency of indiscipline cases emanating from vandalism as low and only $11.8 \%$ of the teachers perceive the frequency of the indiscipline cases associated with vandalism as high. This implies that vandalism is not a significant cause of indiscipline.

On lying, the findings indicate that $18.8 \%$ of the teachers said that frequency of indiscipline cases involving lying is very low, $5.3 \%$ said the cases are low, $17.1 \%$ of the teachers said they are average, $39.4 \%$ said that the cases are high and $19.4 \%$ of the teachers said the frequency of the cases was very high. Cumulatively, the findings indicate that majority of the teachers $(58.8 \%)$ perceive the frequency of indiscipline cases emanating from lying as high and only $24.1 \%$ of the teachers perceive the frequency of the indiscipline cases associated with lying as low. This implies that lying is a significant cause of indiscipline.

Finally, on indecency including indecent clothing and sexual impropriety, the findings indicate that majority of the teachers $(51.8 \%)$ said that frequency of indiscipline cases involving indecency is very low, $24.7 \%$ said the cases are low, $15.3 \%$ of the teachers said they are average, $0.0 \%$ said that the cases are high and $8.2 \%$ of the teachers said the frequency of the cases was very high. Cumulatively, the findings indicate that majority of the teachers $(76.5 \%)$ perceive the frequency of indiscipline cases emanating from indecency as low and only $8.2 \%$ of the teachers perceive the frequency of the indiscipline cases associated with indecency as high. This implies that indecency is not a significant cause of indiscipline.

The fact that indecency is not a significant cause of indiscipline may be attributed to the fact that most of the schools that participated in the study are day schools and thus pupils are subjected to monitoring from parents and the society at home as well as teachers at school. In addition, majority of the pupils are in their formative ages and thus have not been adversely affected by other agents of socialization such as the media and peers. The county DQASO concurred with the findings obtained from the teachers' responses on the cases of indiscipline reported to his office. According to the DQASO, most of the indiscipline cases brought to his attention from the schools involve late coming, chronic absenteeism, fighting and failure to adhere to school rules and regulations.

The findings of the study concur with the findings of past research work carried on the issue of pupils' discipline, for instance, Lochan (2010) identifies most frequent ways through which pupil's indiscipline is expresses as noise making, fighting and failure to complete assigned work. The major indiscipline expressions in schools as use of foul language on other pupils and members of the school community and lying. On the other hand, Grossnicle and Frank (1990) identifies fighting, failure to adhere to instructions and school rules and noisemaking as also main ways through which indiscipline is manifested in primary schools (Grossnicle and Frank, 1990). 


\section{DISCUSSIONS, CONCLUSIONS AND RECOMMENTATION}

The research sought to establish the factors contributing to indiscipline in schools. The study identified 11 different causes of indiscipline that are prevalent in schools. It indicated that absenteeism/ truancy, not finishing homework, use of foul, lying are very prevalent in their schools or classes. Forms of indiscipline including late coming, bullying, stealing, noisemaking, fighting, vandalism and indecency are less prevalent, a finding that was corroborated by the county DQASO and past research work. The examined the prevalence of indiscipline cases in Nyeri Central Sub-County. Specifically, the study sought to examine factors contributing to indiscipline in primary schools. The study adopted descriptive survey research design and was carried in Nyeri Central SubCounty, Kenya. The target population was all the 43 Head teachers from the 43 primary schools, all 572 teachers in primary schools in Nyeri Sub-County, and one DQASO in Nyeri sub-county. A sample of 13 Head teachers and 91 teachers was used. Data was collected using two of the data collection instruments; questionnaire administered to the teachers and the Head teachers and interview schedule will be subjected to the DQASO. A total of 74 duly filled questionnaires were returned representing $92.4 \%$ response rate and was considered adequate for the study.

The analysis of the sample indicated that majority of the teachers sampled had long experience having taught for many years and that every job position was represented in the sample implying that balanced and reliable responses could be obtained from the sample. Majority of the head teachers had long headship experience and had relatively high academic qualifications implying that they would be in a position to give reliable responses. Analysis of the schools indicated that the class sizes were relatively big compared to the approved class size of 35 pupils in primary school. This was likely to impact on the ability of the teacher to manage discipline in their classes effectively.

The study identified 11 different causes of indiscipline that are prevalent in schools. It indicated that absenteeism/ truancy, not finishing homework, use of foul, lying are very prevalent in their schools or classes. Forms of indiscipline including late coming, bullying, stealing, noisemaking, fighting, vandalism and indecency are less prevalent, a finding that was corroborated by the county DQASO.

Based on the findings of the study, the following recommendations are made; first that workshops and seminars need to be organized regularly in order to create awareness on the prevalence of some forms of indiscipline in the schools. These meetings will help in sensitizing the teachers, parents and other stakeholders on ways of curbing the prevalent forms of indiscipline in the area.

Secondly, teachers need to be equipped with the necessary support in order to help them keep good records of indiscipline as well as impart the necessary life skills to pupils.

Thirdly, the teachers need to be trained on the moral, spiritual and social aspects and the changing disciplinary methods. This will enhance the adoption and implementation of alternative disciplinary methods.

Fourthly, and finally, other stakeholders such as education officials, religious institutions as well as other agents of socialization need to be involved and actively involved in discipline mitigation of pupils.

\section{REFERENCES}

Ajzen, I. (1991). The theory of planned behavior. Organizational Behavior and Human Decision Processes, 50(2), 179211. https://doi.org/10.1016/0749-5978(91)90020-T

Basic Education Act (2013). No. 4 of 2013, 4(36).

Boroffice, O. B. (2003) Recreation and Health Behaviour of Adolescents. In Contemporary issues and Researches on Adolescents (Edited by I. A. Nwanuoke, O. Bampgbose \& O. A. Moronkola). Ibadan (Omoade Printing Press) pp 110-126.

Cheunyane, G., (2008). Substance abuse at school. City Press, 31 July 2008.

Donga, M. (1998). The Causes and Consequences of Indiscipline in Public and Independent Secondary Schools. Main Dissertation and Afrikaans University.

Etesi, M. (2012). Curbing Students Indiscipline in Learning Institution. Nairobi; Shrend Publishers Ltd.

Evans, D. and Miguel, E. (2004). Orphans and Schooling in Africa: A Longitudinal Analysis. BREAD Working Paper No. 56. Bureau for Research and Economic Analysis of Development, Cambridge, MA.

Government of Kenya (2001). The Education Act (School Discipline) Chapter 211 Legal Notice No.56 of 2001, the Education Discipline (Amendments) regulation 2001.

Government of Kenya (2001). Report of the Taskforce on Student Indiscipline and Unrest (Wangai Report)

Government of Kenya (2003). The Education Bill 2003 Zero Draft.

Grossnickle, D. and Frank, P. (1990). Prevent the discipline for effective teaching and learning. A source book for teachers and administrators. Resten, Virginia. 
Hogg, M. and Reid, S. (2006). Social identity, self-categorization, and the communication of group norms. Communication Theory, 16(1), 7-30. https://doi.org/10.1111/j.1468-2885.2006.00003.x

Kyungu, S. (2001). Education Enrolment and W astage. MOESR, Nairobi.

Lochan, D. (2010). Student Perceptions of Indiscipline at three primary schools in one Educational District in Central Trinidad. Thesis University of West Indies. Faculty of Humanities and Education.

Lynskey, M., Hall, W. and Louis, D. (2003). Testing hypotheses about the relationship between cannabis use and psychosis. Drug and Alcohol Dependence, 71(2003), 37-48. https:// doi.org/10.1016/S0376-8716(03)00064-4

Maphosa C. (2011). Learners' Views on the Effects of Disciplinary Measures in South African School. Journal of Social Sciences. 28(3), 153-160. https:// doi.org/10.1080/09718923.2011.11892940

Maphosa, C. and Mammen, J. (2011). How Chaotic and Unmanageable Classrooms Have Become: Insights into Prevalent Forms of Learner Indiscipline in South African Schools. The Anthropologist, 13(3), 185-193. https://doi.org/10.1080/09720073.2011.11891196

Ministry of Education Science and Technology, Republic of Kenya (MOEST). (2005). Kenya Educational Sector Support Programme 2005-2010: Delivering Quality Education and Training to all Kenyans. Nairobi. MOEST.

Mugenda, O. and Mugenda, A. (1999). Research Methods: Quantitative and Qualitative Approaches. Laba Graphics Services Ltd; Nairobi.

Nakpodia, E. (2010). The Influence of Principals' Leadership styles on Teachers in Nigeria Secondary. Academic Leadership Journal. 9(3), 1-7.

Onyechi, K. (2007). Deviant Behaviour as Correlate of Academic Achievement Among Secondary School Adolescents. Implication of Service Delivery in the Education Sector, Issues and Strategies. B.G. Mworugy Ed.

Republic of Kenya (1980). The Education Act Chapter 211 Laws of Kenya (rev. Ed) Nairobi: Government Printers.

Republic of Kenya (2001). The Education Act (School Discipline) Chapter 211 Legal Notice No.56 of 2001, the Education Discipline (Amendments) regulation 2001.

Republic of Kenya (2001). Ministry of Education, Science and technology. Report of the Task Force on Students Discipline and Unrest in Secondary Schools (Wangai Report). Nairobi: Jomo Kenyatta Foundation.

Rwamba P. (2004). Discipline in Scottish secondary schools. Research in Education. 50(3), 145-158.

Thornberg, R. (2008). School children's reasoning about school rules. Research Papers in Education. 23(1), 8. https:// doi.org/10.1080/02671520701651029

UNHCRC (1994). Conventions on the Rights of the Child. UNCRC.

UNESCO (1998). Global Education Digest; comparing education statistics across the World. Montreal: UNESCO Institute of Statistics.

Zubaida, A. (2009). Indiscipline and Its Management Techniques: A Case Study of a Special Education School in Kano State. The Journal of the National Council for Exceptional Children, 11(2), 455-463. 